\title{
Wearable Devices: Current Status and Opportunities in Pain Assessment and Management
}

\author{
Andrew Leroux ${ }^{c}$ Rachael Rzasa-Lynn ${ }^{a} \quad$ Ciprian Crainiceanu ${ }^{b}$ Tushar Sharma ${ }^{a}$ \\ ${ }^{a}$ Department of Anesthesiology, University of Colorado, Aurora, CO, USA; ${ }^{\text {b }}$ Department of Biostatistics, Johns \\ Hopkins University, Baltimore, MD, USA; ' Department of Biostatistics and Informatics, Colorado School of Public \\ Health, Aurora, CO, USA
}

\section{Keywords}

Wearable devices - Accelerometry - Physical function - Pain . Ecological momentary assessment $\cdot$ mHealth

\begin{abstract}
Introduction: We investigated the possibilities and opportunities for using wearable devices that measure physical activity and physiometric signals in conjunction with ecological momentary assessment (EMA) data to improve the assessment and treatment of pain. Methods: We considered studies with cross-sectional and longitudinal designs as well as interventional or observational studies correlating pain scores with measures derived from wearable devices. A search was also performed on studies that investigated physical activity and physiometric signals among patients with pain. Results: Few studies have assessed the possibility of incorporating wearable devices as objective tools for contextualizing pain and physical function in free-living environments. Of the studies that have been conducted, most focus solely on physical activity and functional outcomes as measured by a wearable accelerometer. Several studies report promising correlations between pain scores and signals derived from wearable devices, objectively measured physical activity, and physical function. In addition, there is a
\end{abstract}

known association between physiologic signals that can be measured by wearable devices and pain, though studies using wearable devices to measure these signals and associate them with pain in free-living environments are limited. Conclusion: There exists a great opportunity to study the complex interplay between physiometric signals, physical function, and pain in a real-time fashion in free-living environments. The literature supports the hypothesis that wearable devices can be used to develop reproducible biosignals that correlate with pain. The combination of wearable devices and EMA will likely lead to the development of clinically meaningful endpoints that will transform how we understand and treat pain patients.

(C) 2021 The Author(s)

Published by S. Karger AG, Basel

\section{Introduction}

Healthcare is in the midst of a technological revolution with advances in mobile health technologies (also known as mHealth) that are changing many areas of medical practice. Mobile health technologies broadly refer to a number of methods and tools that collect both subjective data on individuals, typically through phone applications and referred to as ecological momentary assessment

Correspondence to:

Tushar Sharma, tushar.2.sharma@ cuanschutz.edu

karger@karger.com www.karger.com/dib

Karger $\stackrel{\text { ' }}{=}$
2021 The Author(s)

Published by S. Karger AG, Basel

This is an Open Access article licensed under the Creative Common Attribution-NonCommercial-4.0 International License (CC BY-NC) (http://www.karger.com/Services/OpenAccessLicense), applicable to the online version of the article only. Usage and distribution for commercial purposes requires written permission. 
(EMA), and objective data, which are collected via the use of wearable or implantable devices. Wearable devices refer to a host of new health and lifestyle devices that contain biosensors placed on the human body and provide unbiased, continuous, high-resolution health-related measurements. These measurements can be used to provide real-time feedback, guide just-in-time treatment or interventions, monitor within-person changes, and quantify population level characteristics and norms. A novel application of wearable devices with a potentially widespread impact is the assessment of the relationship of selfreported pain with concurrently measured physiometric and physical activity data derived from various bodyworn biosensors and accelerometers, respectively [1]. Currently, the assessment of outcomes in pain patients is largely limited to the use of subjective endpoints, such as numeric pain scores and summaries of self-administered questionnaires, typically collected at a single time point during a clinician visit. These self-reported measures are subject to substantial recall, social desirability, cognitive biases, and measurement error [2-4]. While pain is an inherently subjective experience, the unidimensional pain score is an inadequate assessment of this complex phenomenon and fails to capture the impact of pain on function, thus leading to both undertreatment of pain and at times an overly broad application of pharmacologic therapies. In recognition of this, there has been a recent shift of focus toward the development and utilization of broader outcomes in addition to self-reported pain in clinical practice and clinical trials [5-7]. The combination of wearable device data and EMA has the potential to substantially advance pain research and medical management. Indeed, EMA can provide high-quality, self-reported pain characteristics, combining information on timing and intensity with contextual and environmental information. Physiometric and accelerometry sensors can be used to objectively quantify how, when, and for how long the reported pain interferes with activities of daily living. The combination of wearable devices and EMA will likely lead to the development of clinically meaningful endpoints that will fundamentally transform how we manage and treat pain clinically and develop and test new pain therapeutics in clinical trials.

\section{Wearable Devices in Mobile Health Technologies}

The World Health Organization defines mobile health technologies as "medical and public health practice supported by mobile devices." Mobile health technologies comprise a variety of hardware and software technologies that are currently used in practice, including: (1) mobile devices such as smart phones and tablets for EMA and telemedicine video conferencing and (2) wearable devices including activity (e.g., accelerometers) and heart monitors (e.g., pacemakers). Wearables are worn on the body in direct contact or near the surface of the skin and measure a variety of biosignals including heart rate and electric activity (electrocardiogram), respiratory rate, skin temperature, and physical activity. All of these devices can be used actively by a clinician to monitor and provide rapid healthcare interventions or passively to quantify normative and atypical biological signals in a target population.

The application of mobile health technologies is already established and rapidly expanding in many areas of general public wellness and the practice of medicine. The wide availability of smartphones has led to the increased use of telemedicine, a trend that was accelerated by global public health crises such as the COVID-19 pandemic, which strongly increased social distancing and the demand for medical services over the internet. Wearable devices are widely accepted and used in mainstream culture, a trend that was fueled by the wide availability of commercial products such as the Apple Watch and Fitbit.

Wearable technology is rapidly evolving, with newer devices being capable of recording multiple biosignal measurements that could provide a more comprehensive and detailed quantification of the health status of an individual, including measures of sleep [8-10], weight management $[11]$, aging $[12,13]$, and mental health $[14$, 15]. Such devices are already used to better contextualize and understand patient health in a variety of medical specialties, including heart rate and EKG analysis [16-18], which may facilitate the early diagnosis of arrhythmias in cardiology [19-23], the assessment of Parkinson progression [24], multiple sclerosis [25], epilepsy [26, 27], and stroke rehabilitation $[28,29]$ in neurology, and sweatbased glucose monitoring [30] for patients with diabetes [31-33], among others. The number and type of measurements are also rapidly expanding, with some devices targeting $\mathrm{pH}$, lactic acid, and electrolytes such as sodium and potassium on the surface of the skin [34]. Some of these technologies are more mature than others, and much research is still needed to ensure that such measurements can be used as biomarkers for clinical decision making and clinical trials. Among the most mature and accepted mobile technologies are EMA, accelerometrybased assessment of physical activity, heart rate and ECG monitors, GPS trackers, and implantable continuous glucose monitors. 
In the field of pain treatment and research, the standard is to use subjective feedback from patients obtained at scheduled clinical visits or when spontaneously reported. Thus far, very little research has been done to investigate the potential use of wearable devices to complement the assessment and treatment of painful conditions. This provides an opportunity to investigate the potential of wearable devices to provide new insights into the physiologic responses associated with the experience of pain. As both measurements can be obtained dynamically, this provides the opportunity to investigate the context, magnitude, and directionality of the association between reported pain and physiological responses. These physiologic responses may further provide a window into the complex processes underlying the phenomena of pain and suffering. The use of wearable devices in pain research is not a question of if but rather when they will start to be widely used and how they will function as reliable and reproducible tools for pain management and research. To be widely accepted, biomarkers obtained from wearable devices will have to go through the same processes established for all biomarkers used in medical and public health practice $[35,36]$.

\section{Pain: a Core Determinant of Quality of Life}

Pain, as defined by the International Association for the Study of Pain (IASP), is "an unpleasant sensory and emotional experience associated with, or resembling that associated with, actual or potential tissue damage" [37]. Pain is often associated with a negative emotional experience [38]; it is a daily reality of life for many and significantly reduces the quality of life $[39,40]$. Pain can be classified as acute, lasting $<12$ weeks, or chronic, lasting more than 12 weeks or beyond the expected healing time for an acute injury. The pain response is considered to be a protective biofeedback mechanism of the body during the acute phase, with a preventative role in avoiding further injury and giving tissue the opportunity to heal $[41,42]$. Chronic pain develops when noxious conditions persist or these feedback loops are remodeled through both peripheral and central sensitization, even after tissue healing $[43,44]$. The health statistics on pain are staggering; approximately 50 million Americans, or 1 in 5 individuals, suffer from chronic pain, with 20 million suffering from high-impact chronic pain that interferes with work or life $[45,46]$.

Pain is often described as a biopsychosocial phenomenon, reflecting the complex interplay between the trans- mission of electrical signals from the periphery and the individual's psychological and social factors that modulate the experience of pain. It has been well documented that pain is associated with significant psychosocial effects such as worsened sleep, anxiety and depression, and adversely effects on family, work, and social relationships. These psychosocial factors in turn aggravate an individual's pain and exacerbate pain complaints, resulting in a worsened cognitive function, decreased physical activity, and ultimately disability and a poor quality of life [47, 48]. Pain is also thought to play a significant role in the current opioid epidemic in the USA. Acute and chronic pain after surgical interventions is thought to be one of the gateway mechanisms for opioid exposure that in many cases leads to opioid overuse, abuse, dependence, and ultimately death $[49,50]$.

\section{Pain Assessment: Current Status and the Limits of Current Outcome Measures}

To date, there are no objective measures for assessing pain in clinical practice. Specifically, there exist no objective tools to support clinicians in assessing: (1) whether someone is in pain, (2) the intensity of pain, (3) how pain impacts the patient's daily activities, and (4) whether a particular intervention, such as an interventional procedure or a medication, provides a meaningful reduction of pain. Instead, the current gold standard for evaluating pain clinically relies solely on self-reported pain scales such as the Numeric Pain Rating Scale (NPRS) and selfadministered questionnaires on physical function such as the Western Ontario and McMaster Universities Osteoarthritis Index (WOMAC), the Oswestry Disability Index, the Roland Morris Disability Questionnaire for low back pain, and the Neck Disability Index, among others. These tools are limited to assessing specific diseases or isolated pain regions, though some generalizable and customizable surveys exist, including the Pain Interference assessments from the Patient-Reported Outcomes Measurement Information System (PROMIS). Quantification of pain solely based on the patient's self-report has been used historically because of the inherently individualistic and subjective nature of pain, which develops as a result of a multifaceted mechanism involving not just the intensity and duration of tissue damage but also the intricate interplay between biology, psychology, and the environment [47]. Currently, changes in such measures are the standard used in clinical practice for tracking patient progress following interventions such as physical thera- 
py, medications, and procedures. These questionnaires ultimately still rely on the patient's subjective assessment, which is subject to memory, cognitive, social desirability, and other psychologically influenced response biases [51-55].

In addition to biases in patients' self-reported data, there are further limitations in specific populations. For example, young children and older adults with cognitive impairments may not be capable of self-reporting accurately or at all $[56,57]$. Further, when assessing self-reported pain clinically, there is the potential for subjective bias on the part of clinicians. Numerous studies have shown that racial disparities in the treatment of pain exist, with nonwhite patients being less likely to receive opioids as part of pain treatment in both acute and chronic settings [58-63]. Other forms of disparities in pain treatment include age-related bias, with older adults being less likely to receive pain medications for pain compared to younger adults [64], and socioeconomic bias, with a lower socioeconomic status influencing clinician decision making in pain treatment [65]. While clinicians should receive antibias training and such training can help reduce disparities in pain care [66], biases may persist. The development of objective measures of pain could help to inform and contextualize a patient's overall status and limit the effects of clinician biases. Beyond the implications of bias in self-reported measures for clinical practice, these biases may contribute to the large placebo effect often observed in clinical trials of pain interventions, as smaller placebo responses have been noted with standardized tests measuring functional outcomes [67]. Large placebo effects are a pervasive challenge in the identification of effective new treatments for a wide range of painful conditions. Measured endpoints derived from wearable devices should be investigated for placebo effects, but the lower magnitude of placebo effects observed in other functional outcomes suggests that objective endpoints may have lower placebo effects than self-reported outcomes.

Given the limitations of subjective self-reported measures of pain, there has been increasing interest in pain treatment informed by objectively measurable functional outcomes. While many areas of medicine have developed meaningful biomarkers and endpoints to objectively treat patients, the development of objective biomarkers in pain has been lacking [68]. Recently, fMRI was correlated with patient-reported pain intensity following noxious stimuli and can successfully discern noxious stimuli from the sensation of warmth, pain anticipation, and pain recall with a high sensitivity and a high specificity (93\% or high- er for both). fMRI was least associated with social pain, measured by patients being shown images of ex-partners and close friends, with sensitivity of $85 \%$ and a specificity $73 \%$ [69]. However, such hospital-based, controlled imaging studies are not feasible for assessing ongoing realtime objective markers of pain. In contrast, studies using wearable accelerometers to assess pain and function in patients in a free-living environment suggest that objective biomarkers of activity could be developed [70]. Work has also been done to develop objective biosignals for pain in the ICU setting via video monitoring of patient facial expressions for the presence and intensity of pain [71]. We conclude that complementing, if not replacing, subjective in-clinic pain assessment with subjective EMA coupled with objective measures of functional outcomes is both possible and inexorable.

Indeed, in 2016, The Initiative on Methods, Measurement, and Pain Assessment in Clinical Trials (IMMPACT) and Outcome Measures in Rheumatology (OMERACT), issued recommendations for the assessment of physical function in pain clinical trials to include the use of both patient-reported and objective, performance-based measures [72]. Several validated measures of physical function have been utilized to evaluate treatment responses in arthritis or following surgical interventions. These include measures of muscle strength and range of motion, as well as more global assays of function such as the 6-min walk test and the Timed Up and Go test. Although these measures may be valid across a wide range of pain conditions, they are infrequently utilized as primary outcomes in trials of pain interventions and do not provide information about the patient's daily function in their home environment, where the impact of treatment side effects such as sedation may become more apparent $[73,74]$.

\section{Pain and Wearable Devices: the Promising Road Ahead}

Wearable devices provide an opportunity to improve the framework for assessing outcomes relevant for patients with pain in both clinical and research settings. Not only does pain induce a sympathetic physiologic response wherein increased pain leads to increased heart rate, respiratory rate, and blood pressure values among other physiological measures $[75,76]$, but the sympathetic nervous system may also mediate pain, with sympathetic stimulation increasing pain, as seen in patients with complex regional pain syndrome (CRPS) $[77,78]$. This bidirectional relationship between pain and the autonomic 
nervous system results from the triggering of a protective sympathetic response that serves to prevent further tissue damage after stimulation of nociceptive pain receptors in the periphery by acute injury [79] as well as colocalization of pain fibers from the periphery with sympathetic fibers to the central nervous system. Wearable devices can be used to objectively capture one or several of these physiological responses, which could provide insight into the timing and intensity of pain episodes and help to further our understanding of both acute and chronic pain states. Such measurements may further be enhanced by pairing them with EMA of pain, which could provide context for both the enacted effects of pain in the free-living environment and proximal causes of the onset of increased or decreased pain.

There is currently limited work in the field of pain and wearable devices. Some work has been done to investigate differences in physical activity patterns measured by wearable accelerometers, comparing pain patients versus healthy controls. A 2019 meta-analysis by Davergne et al. [80] reviewed 17 studies on the use of wearable activity trackers in patients with rheumatic and musculoskeletal disease (osteoarthritis and low back pain) and found that wearable activity trackers significantly increase the number of steps and time spent in physical activity, but the authors noted that, compared to controls, pain increased with long-duration studies $>8$ weeks, though no comparison was made between changes in activity and changes in pain scores. The meta-analysis of Davergne et al. [80] combined a heterogeneous mix of pain pathologies. A comparison of studies by patient pathologies and interventional strategies yielded additional insights. Li et al. [81] found that intervention with a wearable accelerometer and biweekly coaching did improve physical activity among knee osteoarthritis patients. In a similarly designed study, Li et al. [82] investigated the use of a wearable accelerometer with biweekly coaching by a physical therapist for 4 weeks and did not find any significant improvement in physical activity among a combined patient group with rheumatoid arthritis (RA) and systemic lupus erythematous. However, a post hoc analysis revealed differential results between the pain subpopulations, with RA but not systemic erythematous patients seeing notable treatment effects in moderate to vigorous physical activity and decreased pain. Similarly, these findings of improvement in physical activity among RA patients using a combined behavioral and wearable accelerometer intervention were also seen in the study of Katz et al. [83]. In comparison, McDermott et al. [84]. also considered a combined behavioral and wearable accelerometer inter-

Wearable Devices in Pain Management ventional design among patients with peripheral arterial disease and found no significant intervention effect on either the steps walked or the 6-min walk distance. Taken together, these findings suggest a few possibilities. First, combined behavior and wearable intervention strategies may be condition specific. Exercise intervention feedback appears to be effective in increasing physical activity and or function among patients with RA and osteoarthritis but not in patients with systemic lupus erythematous and peripheral arterial disease, though these studies had small to moderate samples sizes which could result in spurious associations. Second, the exact behavioral component of these interventions varies from study to study, making comparisons challenging.

While there are a number of studies comparing sensor data between patients with pain and healthy controls as noted in the previous paragraph, there are few studies directly associating pain scores with wearable sensor data. We identified a total of 16 such studies since 2015, almost all of which exclusively considered physical activity measured by accelerometer as their sensor data. A summary of these studies is presented in Table 1 . These studies investigate very different populations and pain conditions (e.g., postoperative pain, sickle cell pain, arthritis pain, fibromyalgia, and critical illness). To the extent that the studies included in Table 1 are comparable, the results are mixed. First, consider observational studies of activity and pain. Neither Murphy et al. [85] nor Nørgaard et al. [86], who studied patients with knee/hip osteoarthritis and juvenile idiopathic arthritis, respectively, found associations between the average volume of physical activity and average pain. Interestingly, Murphy et al. [85] found that momentary activity was significantly positively associated with momentary pain. This finding lends credence to the hypothesis that contextualization of pain using concurrently measured accelerometry data may provide further insights beyond consideration of longterm averages or single time point analyses. Perraudin et al. [70] also studied patients with arthritis but used wearable accelerometers to assess the duration of an unsupervised 5 Times Sit to Stand Test in the morning, and they found that the duration of the test was significantly associated with pain, particularly upon waking and overnight. In relation to postoperative pain, Patterson et al. [87] found that decreased postoperative activity was associated with a greater reduction in pain scores among patients who underwent knee and hip replacements.

In contrast, several studies have found that measured changes in activity are not directly associated with changes in pain. Mobbs et al. [88] found that the walking dis- 


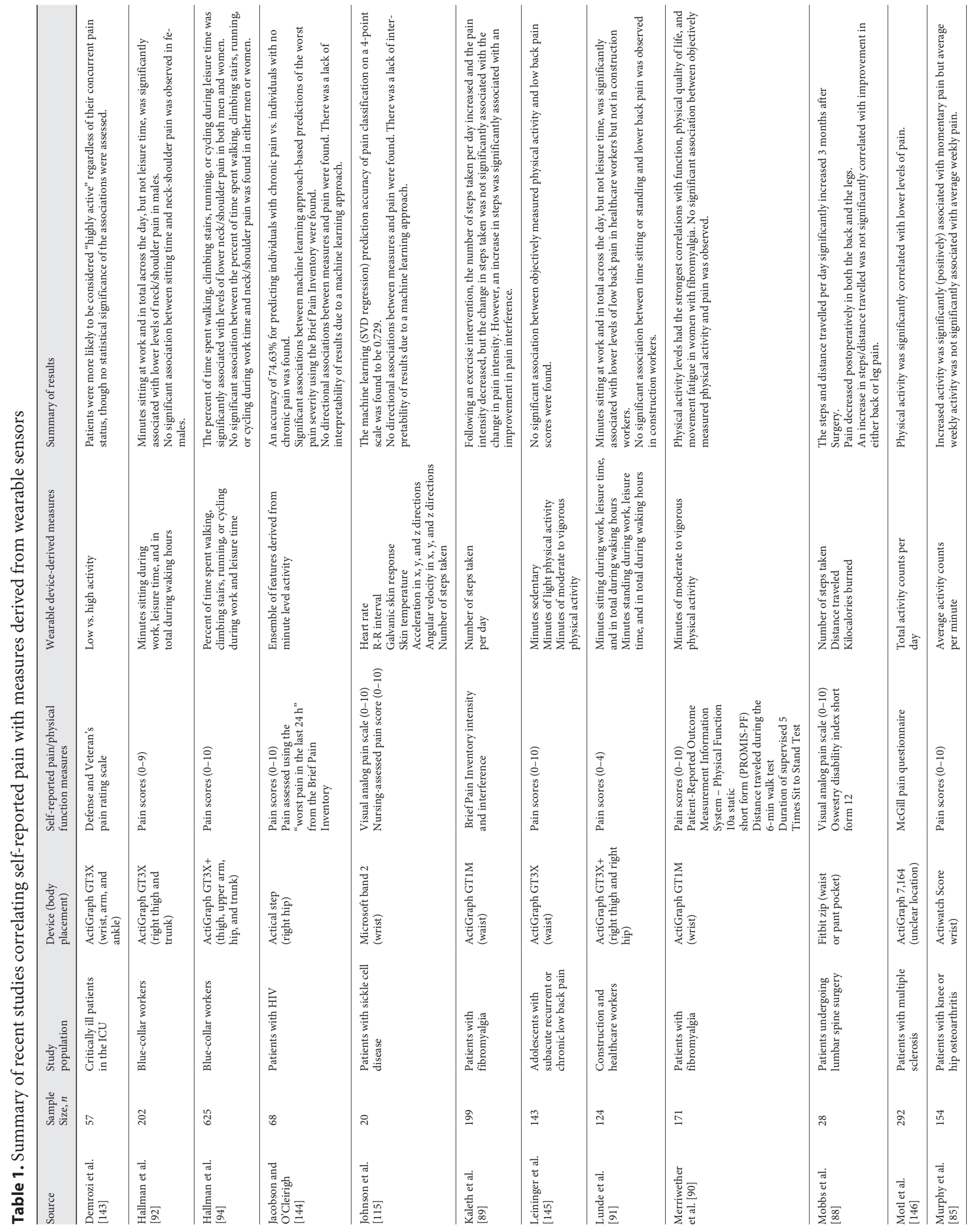




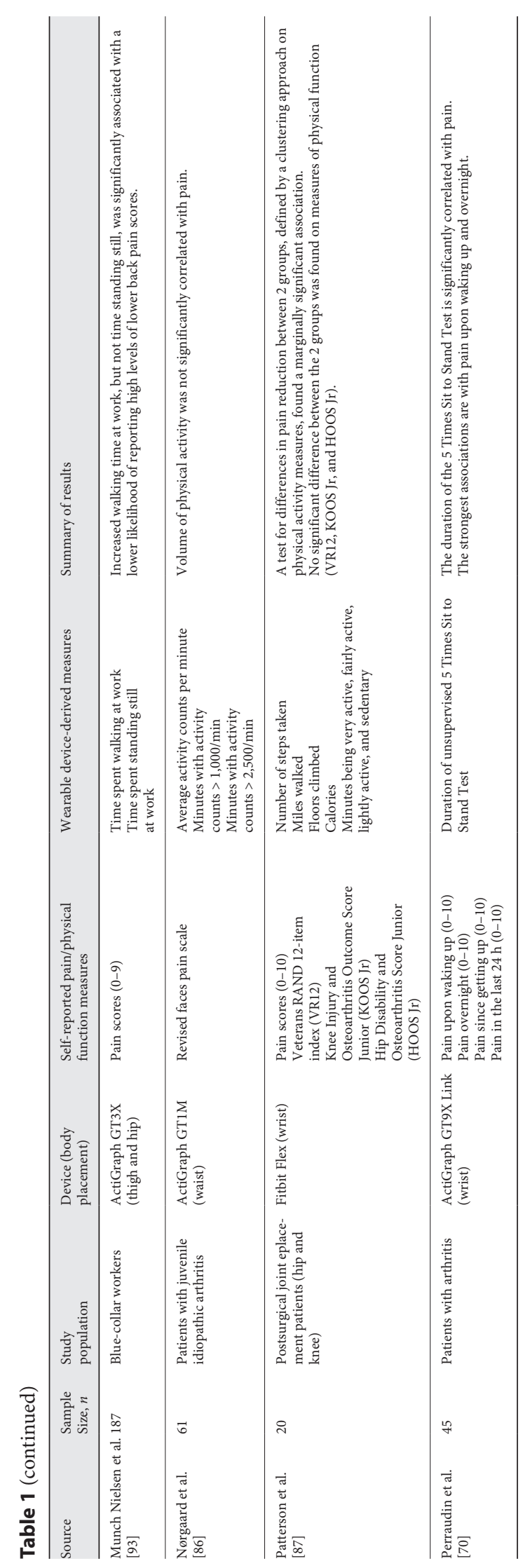

Wearable Devices in Pain Management tance increased and the pain decreased postoperatively following lumbar spine surgery, but the change in walking distance was not significantly associated with improvement in pain. In a study involving an exercise intervention in patients with fibromyalgia, Kaleth et al. [89] found that the steps taken per day increased and the pain decreased, but the change in steps was not associated with pain intensity. In a different observational study of patients with fibromyalgia, Merriwether et al. [90] found no relationship between moderate to vigorous physical activity and pain, though physical activity was associated with physical function and quality of life. In a study of construction and healthcare workers, Lunde et al. [91] found a significant association between the total daily time sitting at work and levels of low back pain in healthcare but not in construction workers, while a study of blue-collar workers by Hallman et al. [92] found that time sitting at work, but not during leisure time, was associated with levels of neck/shoulder pain in men but not in women. Further conflicting results were found when considering the active time at work among blue-collar workers. Munch Nielsen et al. [93] found that increasing the walking time at work was associated with lower levels of back pain, while Hallman et al. [94] found no association between time active at work (walking, climbing stairs, running, or cycling) and neck/shoulder pain scores.

These results suggest a few possibilities, i.e., (1) contemporaneous (or nearly contemporaneous) physical activity is most associated with current pain, (2) there are differential associations between types of activity and pain conditions/locations and these associations differ by context (e.g., occupational activity vs. leisure time activity), (3) results are simply not comparable due to different study conditions despite ostensibly similar populations, and (4) observed effect sizes are small and the results are not reproducible. Given the known associations between pain and physical activity, we believe that the most likely explanation for the at times conflicting results seen in the literature is a combination of (1) and (2) above. Moreover, of the studies presented in Table 1, only those by Murphy et al. [85] and Perraudin et al. [70] measured pain via EMA concurrently with wearable data. Interestingly, those 2 studies both found associations between pain and physical activity or function that suggest the importance of considering temporal dynamics. Specifically, Murphy et al. [85] found that instantaneous physical activity was positively associated with pain, but patient average pain and average activity were not significantly associated, suggesting that increased activity may aggravate patients' current osteoarthritis related pain. Perraudin et 
al. [70] showed that the duration of the unsupervised 5 Times Sit to Stand Test measured using accelerometry in the morning was positively associated with pain on waking and overnight, but not later in the day, suggesting a temporal dynamic whereby fluctuations in pain or the underlying disease affect near term physical function but do not predict global daily pain. Taken together, these 2 studies show promise for incorporation of wearable devices and EMA of pain to better understand the temporal patterns of chronic pain as well as the effects of pain on function and vice versa. Even more information may be learned by targeting biosignals beyond physical activity such as physiologic measures and possibly collecting additional EMA data beyond pain (e.g., current mood, current environment, and recent medication use) for contextualization of individuals' current mental and physical status.

While more information may be gained from wearable devices beyond accelerometry, accelerometry data will be an integral part of any comprehensive approach incorporating wearable sensors and EMA of pain, as wearable accelerometers measure aspects of health and behavior that may be directly related to pain and are relevant to patients in pain. Specifically, wrist-worn accelerometers have been used to estimate sleep features [95-102] in addition to physical activity. Sleep has a bidirectional relationship with pain; disordered sleep may predispose patients to increased pain and pain (and its treatments) may disrupt sleep $[103,104]$. While physical activity and the related construct of physical function are comparatively well studied, the dynamics between accelerometry-measured sleep and EMA of pain have undergone limited investigation. Some studies have associated subjective sleep characteristics with EMA of pain. Two studies found that sleep quality is associated with pain intensity the following day $[105,106]$. Currently, sleep and physical activity research using wearable accelerometers are performed separately, and combining these areas will be a key methodologic challenge in the context of pain data due to the likely multidirectional causal relationship between pain, activity, and sleep.

Despite the clear value of accelerometry in the study of pain, physical activity alone is likely inadequate to characterize pain due to the complex interplay between physical activity, physiology, and perceived pain. For example, physical activity directly influences the heart rate while potentially exacerbating painful conditions. In addition, the experience of pain induces a stress response leading to an increased heart rate and likely decreased physical activity. Moreover, there are physiologic signals that op- erate independently of physical activity which are associated with the experience of pain. Specifically, severe pain has been associated with different patterns in cardiovascular parameters upon orthostatic challenge compared with more mild pain [107]. Moreover, resting heart rate variability (HRV) is altered in several chronic pain states [108-110], and resting HRV may be related to endogenous pain modulation [111]. For example, in patients with fibromyalgia, pain anxiety and pain severity both predict HRV [112]. While some pain conditions are associated with disruptions in the autonomic nervous system that may alter HRV, HRV may also reflect treatment responses. Among patients who experienced relief of chronic low back or leg pain after an epidural steroid injection compared to those who did not, there was a significant change in the measure of HRV in $89 \%$ of the responders [113]. Additionally, HRV changed in the first hour following radiofrequency ablation of the cervical or lumbar medial branch nerves in patients with chronic neck or low back pain [114], but it was not evaluated whether this correlated with reductions in pain scores among individual patients. When assessing HRV as a biomarker for pain in patients, researchers should carefully consider other potential physiologic systems which may influence HRV independently of pain. For example, HRV may reflect dysfunction of the autonomic nervous system rather than perceptions of pain.

Recently, it was shown that physiologic biosignals from wearable devices during inpatient admission for acute sickle cell pain crisis can successfully predict patient-reported pain scores with a cross-validated accuracy of up to $73 \%$ when grouping pain scores into 4 discrete levels [115]. Discovering and analyzing metrics associated with pain physiology may lead to objective endpoints for pain treatment and management. Moreover, early prediction of imminent sickle cell pain crises may be possible, allowing for the development of just-in-time adaptive interventions. Just-in-time adaptive interventions use continuously collected data made available through sensors, accelerometers, mobile applications, and questionnaires to provide "at the moment" intervention and they are currently used for behavioral health changes like weight management and smoking cessation $[116,117]$. Sickle cell pain crises occur following a graduated series of subclinical events within the vasculature [118-120]. It is possible that there are biomarkers in physiometric data and physical activity that are correlated with these subclinical events and can in turn be used to build prediction models. An accurate prediction model may allow for early patient notification of a possible pain crisis and suggest 
home treatments (fluids, medication, and rest) [121], possibly reducing the severity of the pain crisis, avoiding a fulminant vaso-occlusive event and the need for hospitalization.

More broadly, a promising opportunity for advancing the science of pain via wearable technology is in predicting the onset of an acute pain crisis. In the field of cardiology, wearable devices have shown promise in predicting hospitalization in patients with heart failure up to 10 days preceding the event [122]. Extending and applying these principles to pain research could lead to models capable of predicting a pain crisis within a clinically meaningful timeframe. Such a study would require longitudinal follow-up of patients at high risk for a pain crisis, such as those with a disease process like sickle cell anemia or a pattern of frequent emergency department visits for pain. This study would need to abide by best practices for investigations using wearable devices; specifically, investigators would need to carefully consider which device to use, balancing questions of battery life, sampling frequency, biosignals measured, device comfort and location, and participant compliance with wear time protocols.

Moving forward, we propose studies be conducted to assess various biosignals and self-reported pain measures via EMA in a free-living environment among patients with pain. As the experience of pain is unique to each individual, studies can be conducted in which participants serve as their own controls. Specifically, this requires a study period during which participants experience periods of both pain and no pain. This is most easily attained in the setting of planned acute pain, such as postoperative pain; however, acute pain and chronic pain may be associated with vastly different experiences and biosignals, and thus episodic conditions such as migraine or sickle cell pain may also serve as model conditions for study.

There are a number of potential pitfalls researchers may encounter when conducting studies that combine patients' use of wearable devices and collection of EMA data, including self-reported pain. From a practical perspective, both the wearable device and questionnaire assessments must be well tolerated by patients and careful consideration should be given to minimizing the patient burden. In terms of wearable devices, these considerations include, but are not limited to, comfort, body placement, battery time, total wear time, data security, and even aesthetic appeal. Questionnaire assessments should consider both the key constructs most likely associated with, or informative of, condition-specific pain and how to best measure them. Researchers should also consider the timing, frequency, and length of question-

Wearable Devices in Pain Management naires to avoid patient fatigue and improve compliance. Participant burden can be assessed by designing small tolerability and feasibility studies. Moreover, to enhance the comparability of results across studies, an effort should be made to standardize visualizations and widgets (e.g., slider bar vs. self-entering a numeric value) used in the data collection process.

Although we advocate for standardization in EMA, these standards may vary for different pain conditions as particular information may be more relevant for one pain condition as compared to another. A few key pieces of self-reported information are likely relevant to most pain conditions: current pain level, current source of pain, current mood, current energy levels, recent medications taken, sleep quality, and recent activities. In addition, accelerometry-measured sleep and physical activity features are also likely to be relevant for most pain conditions. Additional choices on sensor data collection should be based on condition-specific knowledge about the underling physiology.

There are many different ways to classify pain, i.e., duration (acute, chronic, or episodic), location (headache, back pain, or leg pain), intensity (mild, moderate, or severe), and etiology (nociceptive, neuropathic, or nociplastic). It is our opinion that the best practice for future study designs is to classify patients based on etiology as different types of pain have different mechanisms of action. For example, nociceptive pain, which is pain that results from trauma or inflammation in somatic (e.g., osteoarthritis and sickle cell) or visceral tissue (e.g., pancreatitis and angina), may have biosignals different from those of neuropathic pain, which results from damage to peripheral (diabetic peripheral neuropathy and phantom limb pain) or central nerves (e.g., poststroke and multiple sclerosis) [123-125]. More recently, a third category of pain pathophysiology has been identified, i.e., nociplastic pain (e.g., fibromyalgia and CRPS type 1), which is a hypersensitive pain state without identifiable nerve or tissue damage and is thought to result from central sensitization as a result of persistent neuronal dysfunction [126-128]. Use of this classification system will help to guide researchers in identifying promising potential biosignals to be collected from wearable sensors for investigation.

The complex relationship between pain, physical activity, physiology, psychology, pharmacology, and environmental factors may result in a scenario in which a particular intervention or treatment regime is efficacious in alleviating the patient's pain, allowing them to engage in previously intolerable physical activities, which then aggravates the underlying painful condition, resulting in 
levels of pain and biosignals that are on par with preintervention levels. In such a circumstance, solely analyzing the patient's reported pain or biosignals at a single time point in the absence of continuous physical activity monitoring would fail to detect this relationship. Combining wearable devices with self-reported pain measured by EMA can contextualize these types of events and assess the dynamics of how current and historical patient selfreported measures, activities, and sensor data are associated with both current and future health status.

In addition to the conceptual challenges related to analyzing data with complex interrelations, EMA data are collected multiple times a day over multiple days, creating a hierarchical data structure with observations being correlated within individuals. Data generated by wearable devices also have a hierarchical data structure but they are recorded at a much higher frequency than EMA. Thus, these data are both high dimensional and correlated within the same individual. Indeed, wearable accelerometers can record an acceleration of 100 or more times per second in 3 spatial dimensions, resulting in over 180 million observations per person over a 1-week period. Thus, deriving meaningful, reproducible, and translatable lower dimensional summaries from these data is a key challenge when working with wearable data [129]. Many such summary measures have been proposed and can be readily calculated using open-source methods [130, 131], facilitating comparisons across studies. While not all sensor data are as high dimensional as accelerometry data, care should be taken to create features that are maximally interpretable, particularly when attempting to develop endpoints from sensor data. In this effort, techniques from functional data analysis [132], i.e., the study of high-dimensional, correlated data along a domain (e.g., time of day), can be brought to bear. Indeed, functional data analysis has been successfully applied to accelerometry data in studying the epidemiology of physical activity, aging, and health status [133] as well as predicting the risk of future mortality [134]. These methods range from modelling minute level accelerometry data directly [133-136] to identifying interpretable lower dimensional summaries that capture key features of the sensor data $[134,137]$. Combining methods from functional data analysis with analysis of EMA of pain remains a key methodologic challenge.

Ultimately, multidimensional measures comprised of both subjective and objective data will move into clinical practice and then back into research as validated outcomes of experimental pain interventions. Moving from research to clinical practice will likely be made easier if patients receive some direct benefit from the burden imposed by an- swering EMA questionnaires and wearing the wearable device. We see 2 primary ways to provide value to individual patients. The first is simply through tracking, visualizing, and reporting historical trends and providing associations using patients' own data. However, careful consideration should be given to the potential of these feedback mechanisms to influence patients' behavior, particularly in the context of clinical trials and validation of subjective and objective patient measures. The second is through the development of just-in-time adaptive intervention strategies, drawing from the personalized and contextualized patient status offered through the use of mobile health and sensor technologies to potentially offer patients real-time treatment and support [138]. Just-in-time adaptive interventions are increasingly being used in areas of behavioral health such as for smoking cessation, diet modification, and improved physical activity [139-142]. In the context of pain patients, there is potential for these treatment strategies to help improve physical activity, better manage the interplay between activity and pain cycles, improve the utilization of medication management, and ultimately help to improve how we understand pain patients in the real world and contextualize their care.

\section{Conclusion}

With the increasing availability and prevalence of both consumer and research grade wearable devices, there exists an opportunity to develop novel methods for: (1) characterizing patients' pain in response to treatment, (2) identifying new clinical endpoints for pain patients, (3) understanding the correlates and causal determinants of onset and duration of pain, and (4) predicting the onset of future pain states. These 4 opportunities are plausibly achievable by combining pain scores collected via EMA with concurrently and continuously measured features derived from wearable sensors. Future research in these areas would fundamentally change the development of new treatments and improve our current understanding and treatment of pain patients. The challenge is not whether wearable devices will provide useful clinical information but rather when we will start to use them in practice to improve the field of pain.

\section{Statement of Ethics}

This paper reflects the authors' own research and analysis in a truthful and complete manner. All sources used are properly disclosed (correct citation). 


\section{Conflict of Interest Statement}

Dr. Ciprian Crainiceanu is consulting with Bayer and Johnson and Johnson on methods development for wearable devices in clinical trials. The details of the contracts are disclosed through the Johns Hopkins University eDisclose system and have no direct or apparent relationship with this paper.

\section{Funding Sources}

This research was supported by a National Institute on Aging Training Grant (T 32 AG000247).

\section{Author Contributions}

All of the authors were personally and actively involved in substantial work leading to this paper and take public responsibility for its content.

\section{References}

1 Naranjo-Hernández D, Reina-Tosina J, Roa LM. Sensor Technologies to Manage the Physiological Traits of Chronic Pain: A Review. Sensors (Basel). 2020 Jan;20(2):365.

2 Stroud MW, Thorn BE, Jensen MP, Boothby JL. The relation between pain beliefs, negative thoughts, and psychosocial functioning in chronic pain patients. Pain. 2000 Feb;84(2-3): 347-52.

3 Marty M, Rozenberg S, Legout V, DurandZaleski I, Moyse D, Henrotin Y, et al.; Section Rachis de la Société Française de Rhumatologie; Belgium Back Society. Influence of time, activities, and memory on the assessment of chronic low back pain intensity. Spine. 2009 Jul;34(15):1604-9.

4 Orhan C, Van Looveren E, Cagnie B, Mukhtar NB, Lenoir D, Meeus M. Are Pain Beliefs, Cognitions, and Behaviors Influenced by Race, Ethnicity, and Culture in Patients with Chronic Musculoskeletal Pain: A Systematic Review. Pain Physician. 2018 Nov;21(6):54158.

5 Dosenovic S, Jelicic Kadic A, Jeric M, Boric M, Markovic D, Vucic K, et al. Efficacy and Safety Outcome Domains and Outcome Measures in Systematic Reviews of Neuropathic Pain Conditions. Clin J Pain. 2018 Jul;34(7):67484.

6 Boric K, Jelicic Kadic A, Boric M, ZarandiNowroozi M, Jakus D, Cavar M, et al. Outcome domains and pain outcome measures in randomized controlled trials of interventions for postoperative pain in children and adolescents. Eur J Pain. 2019 Feb;23(2):389-96.

7 Pogatzki-Zahn E, Schnabel K, Kaiser U. Patient-reported outcome measures for acute and chronic pain: current knowledge and future directions. Curr Opin Anaesthesiol. 2019 Oct;32(5):616-22.

8 Pulantara IW, Parmanto B, Germain A. Development of a Just-in-Time Adaptive mHealth Intervention for Insomnia: Usability Study. JMIR Hum Factors. 2018 May;5(2):e21.

9 Guillodo E, Lemey C, Simonnet M, Walter M, Baca-García E, Masetti V, et al.; HUGOPSY Network. Clinical Applications of Mobile Health Wearable-Based Sleep Monitoring: systematic Review. JMIR Mhealth Uhealth. 2020 Apr;8(4):e10733.
10 Roberts DM, Schade MM, Mathew GM, Gartenberg D, Buxton OM. Detecting Sleep Using Heart Rate and Motion Data from Multisensor Consumer-Grade Wearables, Relative to Wrist Actigraphy and Polysomnography. Sleep. 2020 Jul;43(7):zsaa045.

11 Batsis JA, Petersen CL, Clark MM, Cook SB, Lopez-Jimenez F, Al-Nimr RI, et al. A WeightLoss Intervention Augmented by a Wearable Device in Rural Older Adults with Obesity: A Feasibility Study. J Gerontol A Biol Sci Med Sci. 2021 Jan;76(1):95-100.

12 Helbostad JL, Vereijken B, Becker C, Todd C, Taraldsen K, Pijnappels $\mathrm{M}$, et al. Mobile Health Applications to Promote Active and Healthy Ageing. Sensors (Basel). 2017 Mar; 17(3):E622.

13 Kwan RY, Salihu D, Lee PH, Tse M, Cheung DS, Roopsawang I, et al. The effect of e-health interventions promoting physical activity in older people: a systematic review and meta-analysis. Eur Rev Aging Phys Act. 2020 Apr;17(1):7.

14 Inal Y, Wake JD, Guribye F, Nordgreen T. Usability Evaluations of Mobile Mental Health Technologies: systematic Review. J Med Internet Res. 2020 Jan;22(1):e15337.

15 Lecomte T, Potvin S, Corbière M, Guay S, Samson C, Cloutier B, et al. Mobile Apps for Mental Health Issues: Meta-Review of MetaAnalyses. JMIR Mhealth Uhealth. 2020 May; 8(5):e17458.

16 Pevnick JM, Birkeland K, Zimmer R, Elad Y, Kedan I. Wearable technology for cardiology: an update and framework for the future. Trends Cardiovasc Med. 2018 Feb;28(2):144-50.

17 Raja JM, Elsakr C, Roman S, Cave B, PourGhaz I, Nanda A, et al. Apple Watch, Wearables, and Heart Rhythm: where do we stand? Ann Transl Med. 2019 Sep;7(17):417.

18 Sana F, Isselbacher EM, Singh JP, Heist EK, Pathik B, Armoundas AA. Wearable Devices for Ambulatory Cardiac Monitoring: JACC State-of-the-Art Review. J Am Coll Cardiol. 2020 Apr;75(13):1582-92.

19 Dagher L, Shi H, Zhao Y, Marrouche NF. Wearables in cardiology: here to stay. Heart Rhythm. 2020 May;17(5 Pt B):889-95.

20 Faragli A, Abawi D, Quinn C, Cvetkovic M, Schlabs T, Tahirovic E, et al. The role of noninvasive devices for the telemonitoring of heart failure patients. Heart Fail Rev. 2020, Online ahead of print.

21 Hochstadt A, Havakuk O, Chorin E, Schwartz AL, Merdler I, Laufer M, et al. Continuous heart rhythm monitoring using mobile photoplethysmography in ambulatory patients. J Electrocardiol. 2020 May - Jun;60:138-41.

22 Cheung CC, Krahn AD, Andrade JG. The Emerging Role of Wearable Technologies in Detection of Arrhythmia. Can J Cardiol. 2018 Aug;34(8):1083-7.

23 Sološenko A, Petrènas A, Paliakaitè B, Sörnmo L, Marozas V. Detection of atrial fibrillation using a wrist-worn device. Physiol Meas. 2019 Feb;40(2):025003.

24 Morgan C, Rolinski M, McNaney R, Jones B, Rochester L, Maetzler W, et al. Systematic Review Looking at the Use of Technology to Measure Free-Living Symptom and Activity Outcomes in Parkinson's Disease in the Home or a Home-like Environment. J Parkinsons Dis. 2020;10(2):429-54.

25 Salimzadeh Z, Damanabi S, Kalankesh LR, Ferdousi R. Mobile Applications for Multiple Sclerosis: a Focus on Self-Management. Acta Inform Med. 2019 Mar;27(1):12-8.

26 Johansson D, Ohlsson F, Krýsl D, Rydenhag B, Czarnecki M, Gustafsson N, et al. Tonicclonic seizure detection using accelerometrybased wearable sensors: A prospective, videoEEG controlled study. Seizure. 2019 Feb;65: 48-54.

27 Regalia G, Onorati F, Lai M, Caborni C, Picard RW. Multimodal wrist-worn devices for seizure detection and advancing research: focus on the Empatica wristbands. Epilepsy Res. 2019 Jul;153:79-82.

28 Lee JY, Kwon S, Kim WS, Hahn SJ, Park J, Paik NJ. Feasibility, reliability, and validity of using accelerometers to measure physical activities of patients with stroke during inpatient rehabilitation. PLoS One. 2018 Dec; 13(12):e0209607.

29 Louie DR, Bird ML, Menon C, Eng JJ. Perspectives on the prospective development of stroke-specific lower extremity wearable monitoring technology: a qualitative focus group study with physical therapists and individuals with stroke. J Neuroeng Rehabil. 2020 Feb;17(1):31. 
30 Lee H, Song C, Hong YS, Kim MS, Cho HR, Kang T, et al. Wearable/disposable sweatbased glucose monitoring device with multistage transdermal drug delivery module. Sci Adv. 2017 Mar;3(3):e1601314.

31 Shan R, Sarkar S, Martin SS. Digital health technology and mobile devices for the management of diabetes mellitus: state of the art. Diabetologia. 2019 Jun;62(6):877-87.

32 Sun C, Malcolm JC, Wong B, Shorr R, Doyle MA. Improving Glycemic Control in Adults and Children With Type 1 Diabetes With the Use of Smartphone-Based Mobile Applications: A Systematic Review. Can J Diabetes. 2019 Feb;43(1):51-58.e3.

33 Wang Y, Min J, Khuri J, Xue H, Xie B, A Kaminsky L, et al. Effectiveness of Mobile Health Interventions on Diabetes and Obesity Treatment and Management: Systematic Review of Systematic Reviews. JMIR Mhealth Uhealth. 2020 Apr;8(4):e15400.

34 Seshadri DR, Li RT, Voos JE, Rowbottom JR Alfes CM, Zorman CA, et al. Wearable sensors for monitoring the internal and external workload of the athlete. NPJ Digit Med. 2019 Jul;2(1):71.

35 Cox SM, Lane A, Volchenboum SL. Use of Wearable, Mobile, and Sensor Technology in Cancer Clinical Trials. JCO Clin Cancer Inform. 2018 Dec;2(2):1-11.

36 Coran P, Goldsack JC, Grandinetti CA, Bakker JP, Bolognese M, Dorsey ER, et al. Advancing the Use of Mobile Technologies in Clinical Trials: Recommendations from the Clinical Trials Transformation Initiative. Digit Biomark. 2019 Nov;3(3):145-54.

37 Raja SN, Carr DB, Cohen M, Finnerup NB, Flor $\mathrm{H}$, Gibson S, et al. The revised International Association for the Study of Pain definition of pain: concepts, challenges, and compromises. Pain. 2020 Sep;161(9):1976-82.

38 Humo M, Lu H, Yalcin I. The molecular neurobiology of chronic pain-induced depression. Cell Tissue Res. 2019 Jul;377(1):21-43.

39 Nahin RL. Estimates of pain prevalence and severity in adults: united States, 2012. J Pain. 2015 Aug;16(8):769-80.

40 Mills SEE, Mills SE, Nicolson KP, Smith BH Chronic pain: a review of its epidemiology and associated factors in population-based studies. Br J Anaesth. 2019 Aug;123(2):e27383.

41 Treede RD, Rief W, Barke A, Aziz Q, Bennett MI, Benoliel R, et al. A classification of chronic pain for ICD-11. Pain. 2015 Jun;156(6): 1003-7.

42 Pozek JP, Beausang D, Baratta JL, Viscusi ER The Acute to Chronic Pain Transition: Can Chronic Pain Be Prevented? Med Clin North Am. 2016 Jan;100(1):17-30.

43 Scholz J. Mechanisms of chronic pain. Mol Pain. 2014;10 Suppl 1:O15.

44 Nijs J, Leysen L, Vanlauwe J, Logghe T, Ickmans K, Polli A, et al. Treatment of central sensitization in patients with chronic pain time for change? Expert Opin Pharmacother. 2019 Nov;20(16):1961-70.
45 Dahlhamer J, Lucas J, Zelaya C, Nahin R, Mackey S, DeBar L, et al. Prevalence of Chronic Pain and High-Impact Chronic Pain Among Adults - United States, 2016. MMWR Morb Mortal Wkly Rep. 2018 Sep;67(36):1001-6.

46 Pitcher MH, Von Korff M, Bushnell MC, Porter L. Prevalence and Profile of High-Impact Chronic Pain in the United States. J Pain. 2019 Feb;20(2):146-60.

47 Dueñas M, Ojeda B, Salazar A, Mico JA, Failde I. A review of chronic pain impact on patients, their social environment and the health care system. J Pain Res. 2016 Jun;9:457-67.

48 Clauw DJ, Essex MN, Pitman V, Jones KD. Reframing chronic pain as a disease, not a symptom: rationale and implications for pain management. Postgrad Med. 2019 Apr; 131(3):185-98.

49 Hah JM, Bateman BT, Ratliff J, Curtin C, Sun E. Chronic Opioid Use After Surgery: Implications for Perioperative Management in the Face of the Opioid Epidemic. Anesth Analg. 2017 Nov; 125(5):1733-40.

50 Glare P, Aubrey KR, Myles PS. Transition from acute to chronic pain after surgery. Lancet. 2019 Apr;393(10180):1537-46.

51 Bellamy N, Buchanan WW, Goldsmith $\mathrm{CH}$, Campbell J, Stitt LW. Validation study of WOMAC: a health status instrument for measuring clinically important patient relevant outcomes to antirheumatic drug therapy in patients with osteoarthritis of the hip or knee. J Rheumatol. 1988 Dec;15(12):1833-40.

52 Sallis JF, Saelens BE. Assessment of physical activity by self-report: status, limitations, and future directions. Res Q Exerc Sport. 2000 Jun;71(Suppl 2):1-14.

53 Washburn RA. Assessment of physical activity in older adults. Res Q Exerc Sport. 2000 Jun;71(2 Suppl):S79-88

54 McConnell S, Kolopack P, Davis AM. The Western Ontario and McMaster Universities Osteoarthritis Index (WOMAC): a review of its utility and measurement properties. Arthritis Rheum. 2001 Oct;45(5):453-61.

55 Kumar P, Tripathi L. Challenges in pain assessment: pain intensity scales. Indian Journal of Pain. 2014 May;28(2):61-70.

56 Tsai PF. Assessing pain in older adults. Gerontol Nurs. 2011 May;37(5):3-4

57 Tsze DS, von Baeyer CL, Bulloch B, Dayan PS. Validation of self-report pain scales in children. Pediatrics. 2013 Oct;132(4):e971-9.

58 Shah AA, Zogg CK, Zafar SN, Schneider EB, Cooper LA, Chapital AB, et al. Analgesic Access for Acute Abdominal Pain in the Emergency Department Among Racial/Ethnic Minority Patients: A Nationwide Examination. Med Care. 2015 Dec;53(12):1000-9.

59 Singhal A, Tien YY, Hsia RY. Racial-Ethnic Disparities in Opioid Prescriptions at Emergency Department Visits for Conditions Commonly Associated with Prescription Drug Abuse. PLoS One. 2016 Aug; 11(8):e0159224.

60 Fain KM, Alexander GC, Dore DD, Segal JB, Zullo AR, Castillo-Salgado C. Frequency and
Predictors of Analgesic Prescribing in U.S Nursing Home Residents with Persistent Pain. J Am Geriatr Soc. 2017 Feb;65(2):286-93.

61 Hunnicutt JN, Ulbricht CM, Tjia J, Lapane KL. Pain and pharmacologic pain management in long-stay nursing home residents. Pain. 2017 Jun;158(6):1091-9.

62 Meints SM, Cortes A, Morais CA, Edwards RR. Racial and ethnic differences in the experience and treatment of noncancer pain. Pain Manag. 2019 May;9(3):317-34.

63 Morales ME, Yong RJ. Racial and Ethnic Disparities in the Treatment of Chronic Pain. Pain Med. 2021 Feb;22(1):75-90.

64 Rasu RS, Knell ME. Determinants of Opioid Prescribing for Nonmalignant Chronic Pain in US Outpatient Settings. Pain Med. 2018 Mar;19(3):524-32.

65 Anastas TM, Miller MM, Hollingshead NA, Stewart JC, Rand KL, Hirsh AT. The Unique and Interactive Effects of Patient Race, Patient Socioeconomic Status, and Provider Attitudes on Chronic Pain Care Decisions. Ann Behav Med. 2020 Oct;54(10):771-82.

66 Hirsh AT, Miller MM, Hollingshead NA, Anastas T, Carnell ST, Lok BC, et al. A randomized controlled trial testing a virtual perspective-taking intervention to reduce race and socioeconomic status disparities in pain care. Pain. 2019 Oct;160(10):2229-40.

67 Huang Z, Chen J, Hu QS, Huang Q, Ma J, Pei FX, et al. Meta-analysis of pain and function placebo responses in pharmacological osteoarthritis trials. Arthritis Res Ther. 2019 Jul;21(1):173.

68 van der Miesen MM, Lindquist MA, Wager TD. Neuroimaging-based biomarkers for pain: state of the field and current directions. Pain Rep. 2019 Aug;4(4):e751.

69 Wager TD, Atlas LY, Lindquist MA, Roy M, Woo CW, Kross E. An fMRI-based neurologic signature of physical pain. N Engl J Med. 2013 Apr;368(15):1388-97.

70 Perraudin CG, Illiano VP, Calvo F, O'Hare E, Donnelly SC, Mullan RH, et al. Observational Study of a Wearable Sensor and Smartphone Application Supporting Unsupervised Exercises to Assess Pain and Stiffness. Digit Biomark. 2018 Oct;2(3):106-25.

71 Lucey P, Cohn JF, Prkachin KM, Solomon PE, Chew S, Matthews I. Painful monitoring: Automatic pain monitoring using the UNBCMcMaster shoulder pain expression archive database. Image Vision Computing. 2012; 30(3): 197-205

72 Taylor AM, Phillips K, Patel KV, Turk DC, Dworkin RH, Beaton D, et al. Assessment of physical function and participation in chronic pain clinical trials: IMMPACT/OMERACT recommendations. Pain. 2016 Sep;157(9):1836-50.

73 Bennell K, Dobson F, Hinman R. Measures of physical performance assessments: SelfPaced Walk Test (SPWT), Stair Climb Test (SCT), Six-Minute Walk Test (6MWT), Chair Stand Test (CST), Timed Up \& Go (TUG), Sock Test, Lift and Carry Test (LCT), and Car Task. Arthritis Care Res (Hoboken). 2011 Nov;63(Suppl 11):S350-70. 
74 Evensen NM, Kvåle A, Braekken IH. Reliability of the Timed Up and Go test and Ten-Metre Timed Walk Test in Pregnant Women with Pelvic Girdle Pain. Physiother Res Int. 2015 Sep;20(3):158-65.

75 Tousignant-Laflamme Y, Rainville P, Marchand S. Establishing a link between heart rate and pain in healthy subjects: a gender effect. J Pain. 2005 Jun;6(6):341-7.

76 Bendall JC, Simpson PM, Middleton PM. Prehospital vital signs can predict pain severity: analysis using ordinal logistic regression. Eur J Emerg Med. 2011 Dec;18(6):334-9.

77 Jänig W. Relationship between pain and autonomic phenomena in headache and other pain conditions. Cephalalgia. 2003;23(1_suppl Suppl 1):43-8.

78 Schlereth T, Birklein F. The sympathetic nervous system and pain. Neuromolecular Med. 2008;10(3):141-7.

79 Burton AR, Fazalbhoy A, Macefield VG. Sympathetic Responses to Noxious Stimulation of Muscle and Skin. Front Neurol. 2016 Jun;7: 109.

80 Davergne T, Pallot A, Dechartres A, Fautrel B, Gossec L. Use of Wearable Activity Trackers to Improve Physical Activity Behavior in $\mathrm{Pa}$ tients With Rheumatic and Musculoskeletal Diseases: A Systematic Review and MetaAnalysis. Arthritis Care Res (Hoboken). 2019 Jun;71(6):758-67.

81 Li LC, Sayre EC, Xie H, Falck RS, Best JR, Liu-Ambrose T, et al. Efficacy of a Community-Based Technology-Enabled Physical Activity Counseling Program for People With Knee Osteoarthritis: Proof-of-Concept Study. J Med Internet Res. 2018 Apr; 20(4):e159.

82 Li LC, Feehan LM, Xie H, Lu N, Shaw C, Gromala D, et al. Efficacy of a Physical Activity Counseling Program With Use of a Wearable Tracker in People With Inflammatory Arthritis: A Randomized Controlled Trial. Arthritis Care Res (Hoboken). 2020 Dec;72(12):175565.

83 Katz P, Margaretten M, Gregorich S, Trupin L. Physical Activity to Reduce Fatigue in Rheumatoid Arthritis: A Randomized Controlled Trial. Arthritis Care Res (Hoboken). 2018 Jan;70(1):1-10.

84 McDermott MM, Spring B, Berger JS, TreatJacobson D, Conte MS, Creager MA, et al. Effect of a Home-Based Exercise Intervention of Wearable Technology and Telephone Coaching on Walking Performance in Peripheral Artery Disease: The HONOR Randomized Clinical Trial. JAMA. 2018 Apr;319(16): 1665-76.

85 Murphy SL, Schepens Niemiec S, Lyden AK, Kratz AL. Pain, Fatigue, and Physical Activity in Osteoarthritis: The Moderating Effects of Pain- and Fatigue-Related Activity Interference. Arch Phys Med Rehabil. 2016 Sep;97(9 Suppl):S201-9.

86 Nørgaard M, Lomholt JJ, Thastum M, Herlin M, Twilt M, Herlin T. Accelerometerassessed daily physical activity in relation to pain cognition in juvenile idiopathic arthritis. Scand J Rheumatol. 2017 Jan;46(1): 22-6.

87 Patterson JT, Wu HH, Chung CC, Bendich I, Barry JJ, Bini SA. Wearable activity sensors and early pain after total joint arthroplasty. Arthroplast Today. 2020 Mar;6(1):68-70.

88 Mobbs RJ, Phan K, Maharaj M, Rao PJ. Physical Activity Measured with Accelerometer and Self-Rated Disability in Lumbar Spine Surgery: A Prospective Study. Global Spine J. 2016 Aug;6(5):459-64.

89 Kaleth AS, Slaven JE, Ang DC. Does increasing steps per day predict improvement in physical function and pain interference in adults with fibromyalgia? Arthritis Care Res (Hoboken). 2014 Dec;66(12):1887-94.

90 Merriwether EN, Frey-Law LA, Rakel BA, Zimmerman MB, Dailey DL, Vance CG, et al. Physical activity is related to function and fatigue but not pain in women with fibromyalgia: baseline analyses from the Fibromyalgia Activity Study with TENS (FAST). Arthritis Res Ther. 2018 Aug;20(1):199.

91 Lunde LK, Koch M, Knardahl S, Veiersted KB. Associations of objectively measured sitting and standing with low-back pain intensity: a 6-month follow-up of construction and healthcare workers. Scand J Work Environ Health. 2017 May;43(3):269-78.

92 Hallman DM, Gupta N, Mathiassen SE, Holtermann A. Association between objectively measured sitting time and neck-shoulder pain among blue-collar workers. Int Arch Occup Environ Health. 2015 Nov;88(8):103142.

93 Munch Nielsen C, Gupta N, Knudsen LE, Holtermann A. Association of objectively measured occupational walking and standing still with low back pain: a cross-sectional study. Ergonomics. 2017 Jan;60(1):118-26.

94 Hallman DM, Birk Jørgensen M, Holtermann A. Objectively measured physical activity and 12-month trajectories of neck-shoulder pain in workers: A prospective study in DPHACTO. Scand J Public Health. 2017 May;45(3): 288-98.

95 Cole RJ, Kripke DF, Gruen W, Mullaney DJ, Gillin JC. Automatic sleep/wake identification from wrist activity. Sleep. 1992 Oct;15(5): 461-9.

96 Lockley SW, Skene DJ, Arendt J. Comparison between subjective and actigraphic measurement of sleep and sleep rhythms. J Sleep Res. 1999 Sep;8(3):175-83.

97 Jean-Louis G, Kripke DF, Mason WJ, Elliott JA, Youngstedt SD. Sleep estimation from wrist movement quantified by different actigraphic modalities. J Neurosci Methods. 2001 Feb;105(2):185-91.

98 Littner M, Kushida CA, Anderson WM, Bailey D, Berry RB, Davila DG, et al.; Standards of Practice Committee of the American Academy of Sleep Medicine. Practice parameters for the role of actigraphy in the study of sleep and circadian rhythms: an update for 2002 . Sleep. 2003 May;26(3):337-41.
99 Blackwell T, Redline S, Ancoli-Israel S, Schneider JL, Surovec S, Johnson NL, et al.; Study of Osteoporotic Fractures Research Group. Comparison of sleep parameters from actigraphy and polysomnography in older women: the SOF study. Sleep. 2008 Feb;31(2):283-91.

100 Girschik J, Fritschi L, Heyworth J, Waters F. Validation of self-reported sleep against actigraphy. J Epidemiol. 2012;22(5):462-8.

101 van Hees VT, Sabia S, Anderson KN, Denton SJ, Oliver J, Catt M, et al. A Novel, Open Access Method to Assess Sleep Duration Using a Wrist-Worn Accelerometer. PLoS One. 2015 Nov;10(11):e0142533.

102 van Hees VT, Sabia S, Jones SE, Wood AR, Anderson KN, Kivimäki M, et al. Estimating sleep parameters using an accelerometer without sleep diary. Sci Rep. 2018 Aug;8(1):12975.

103 Andersen ML, Araujo P, Frange C, Tufik S Sleep Disturbance and Pain: A Tale of Two Common Problems. Chest. 2018 Nov; 154(5):1249-59.

104 Herrero Babiloni A, Beetz G, Bruneau A, Martel MO, Cistulli PA, Nixdorf DR, et al. Multitargeting the sleep-pain interaction with pharmacological approaches: A narrative review with suggestions on new avenues of investigation. Sleep Med Rev. 2021 Jan;59:101459.

105 Hamilton NA, Catley D, Karlson C. Sleep and the affective response to stress and pain. Health Psychol. 2007 May;26(3):288-95.

106 Bromberg MH, Connelly M, Anthony KK, Gil KM, Schanberg LE. Prospective Mediation Models of Sleep, Pain, and Daily Function in Children With Arthritis Using Ecological Momentary Assessment. Clin J Pain. 2016 Jun;32(6):471-7.

107 Davydov DM, Perlo S. Cardiovascular activity and chronic pain severity. Physiol Behav. 2015 Dec;152(Pt A):203-16.

108 Mazurak N, Seredyuk N, Sauer H, Teufel M, Enck P. Heart rate variability in the irritable bowel syndrome: a review of the literature. Neurogastroenterol Motil. 2012 Mar;24(3): 206-16.

109 Meeus M, Goubert D, De Backer F, Struyf F, Hermans L, Coppieters I, et al. Heart rate variability in patients with fibromyalgia and patients with chronic fatigue syndrome: a systematic review. Semin Arthritis Rheum. 2013 Oct;43(2):279-87.

110 Williams DP, Chelimsky G, McCabe NP, Koenig J, Singh P, Janata J, et al. Effects of Chronic Pelvic Pain on Heart Rate Variability in Women. J Urol. 2015 Nov;194(5):1289-94.

111 Van Den Houte M, Van Oudenhove L, Bogaerts K, Van Diest I, Van den Bergh O. Endogenous Pain Modulation: Association with Resting Heart Rate Variability and Negative Affectivity. Pain Med. 2018 Aug; 19(8):1587-96.

112 Mostoufi SM, Afari N, Ahumada SM, Reis V, Wetherell JL. Health and distress predictors of heart rate variability in fibromyalgia and other forms of chronic pain. J Psychosom Res. 2012 Jan;72(1):39-44. 
113 Storella RJ, Shi Y, O'Connor DM, Pharo GH, Abrams JT, Levitt J. Relief of chronic pain may be accompanied by an increase in a measure of heart rate variability. Anesth Analg. 1999 Aug;89(2):448-50.

114 Ye JJ, Chuang CC, Tai YT, Lee KT, Hung KS. Use of Heart Rate Variability and Photoplethysmograph-Derived Parameters as Assessment Signals of Radiofrequency Therapy Efficacy for Chronic Pain. Pain Pract. 2017 Sep;17(7):879-85.

115 Johnson A, Yang F, Gollarahalli S, Banerjee $\mathrm{T}$, Abrams D, Jonassaint J, et al. Use of Mobile Health Apps and Wearable Technology to Assess Changes and Predict Pain During Treatment of Acute Pain in Sickle Cell Disease: feasibility Study. JMIR Mhealth Uhealth. 2019 Dec;7(12):e13671.

116 Spruijt-Metz D, Wen CK, O’Reilly G, Li M, Lee $\mathrm{S}$, Emken BA, et al. Innovations in the Use of Interactive Technology to Support Weight Management. Curr Obes Rep. 2015 Dec;4(4):510-9.

117 Miller CK. Adaptive Intervention Designs to Promote Behavioral Change in Adults: What Is the Evidence? Curr Diab Rep. 2019 Jan;19(2):7.

118 Barabino GA, Platt MO, Kaul DK. Sickle cell biomechanics. Annu Rev Biomed Eng. 2010 Aug;12(1):345-67.

119 Zhang D, Xu C, Manwani D, Frenette PS. Neutrophils, platelets, and inflammatory pathways at the nexus of sickle cell disease pathophysiology. Blood. 2016 Feb;127(7): 801-9.

120 Sundd P, Gladwin MT, Novelli EM. Pathophysiology of Sickle Cell Disease. Annu Rev Pathol. 2019 Jan;14(1):263-92.

121 Darbari DS, Sheehan VA, Ballas SK. The vaso-occlusive pain crisis in sickle cell disease: Definition, pathophysiology, and management. Eur J Haematol. 2020 Sep;105(3):23746.

122 Stehlik J, Schmalfuss C, Bozkurt B, NativiNicolau J, Wohlfahrt P, Wegerich S, et al. Continuous Wearable Monitoring Analytics Predict Heart Failure Hospitalization: The LINK-HF Multicenter Study. Circ Heart Fail. 2020 Mar;13(3):e006513.

123 Treede RD, Jensen TS, Campbell JN, Cruccu G, Dostrovsky JO, Griffin JW, et al. Neuropathic pain: redefinition and a grading system for clinical and research purposes. Neurology. $2008 \mathrm{Apr} ; 70(18): 1630-5$.
124 Costigan M, Scholz J, Woolf CJ. Neuropathic pain: a maladaptive response of the nervous system to damage. Annu Rev Neurosci. 2009;32(1):1-32.

125 Stanos S, Brodsky M, Argoff C, Clauw DJ, D'Arcy Y, Donevan S, et al. Rethinking chronic pain in a primary care setting. Postgrad Med. 2016 Jun;128(5):502-15.

126 Chakravarty A, Sen A. Migraine, neuropathic pain and nociceptive pain: towards a unifying concept. Med Hypotheses. 2010 Feb; 74(2):225-31.

127 Kosek E, Cohen M, Baron R, Gebhart GF, Mico JA, Rice AS, et al. Do we need a third mechanistic descriptor for chronic pain states? Pain. 2016 Jul;157(7):1382-6.

128 Trouvin A-P, Perrot S. New concepts of pain. Best Pract Res Clin Rheumatol. 2019 Jun;33(3):101415.

129 Karas M, Bai J, Strączkiewicz M, Harezlak J, Glynn NW, Harris T, et al. Accelerometry data in health research: challenges and opportunities. Stat Biosci. 2019 Jul;11(2):210-37.

130 Bai J, Di C, Xiao L, Evenson KR, LaCroix AZ, Crainiceanu CM, et al. An Activity Index for Raw Accelerometry Data and Its Comparison with Other Activity Metrics. PLoS One. 2016 Aug;11(8):e0160644.

131 John D, Tang Q, Albinali F, Intille S. An OpenSource Monitor-Independent Movement Summary for Accelerometer Data Processing. J Measur Physical Behav. 2019;2:1-14.

132 Ramsay J, Silverman BW. Functional data analysis. New York: Sringer; 2005.

133 Xiao L, Huang L, Schrack JA, Ferrucci L, Zipunnikov V, Crainiceanu CM. Quantifying the lifetime circadian rhythm of physical activity: a covariate-dependent functional approach. Biostatistics. 2015 Apr;16(2):352-67.

134 Leroux A, Di J, Smirnova E, McGuffey EJ, Cao Q, Bayatmokhtari E, et al. Organizing and Analyzing the Activity Data in NHANES. Stat Biosci. 2019 Jul;11(2):262-87.

135 Goldsmith J, Zipunnikov V, Schrack J. Generalized multilevel function-on-scalar regression and principal component analysis. Biometrics. 2015 Jun;71(2):344-53.

136 Cui E, Crainiceanu CM, Leroux A. Additive Functional Cox Model. J Comput Graph Stat. 2020. doi: 10.1080/10618600.2020.1853550.

137 Smirnova E, Leroux A, Cao Q, Tabacu L, Zipunnikov V, Crainiceanu C, et al. The Predictive Performance of Objective Measures of Physical Activity Derived From Accelerometry Data for 5-Year All-Cause Mortality in Older Adults: National Health and Nutritional Examination Survey 2003-2006. J Gerontol A Biol Sci Med Sci. 2020 Sep;75(9): 1779-85.
138 Nahum-Shani I, Smith SN, Spring BJ, Collins LM, Witkiewitz K, Tewari A, et al. Justin-Time Adaptive Interventions (JITAIs) in Mobile Health: Key Components and Design Principles for Ongoing Health Behavior Support. Ann Behav Med. 2018 May;52(6): 446-62.

139 Patrick K, Raab F, Adams MA, Dillon L Zabinski M, Rock CL, et al. A text messagebased intervention for weight loss: randomized controlled trial. J Med Internet Res. 2009 Jan;11(1):e1.

140 Müller AM, Blandford A, Yardley L. The conceptualization of a Just-In-Time Adaptive Intervention (JITAI) for the reduction of sedentary behavior in older adults. mHealth. 2017 Sep;3:37.

141 Hardeman W, Houghton J, Lane K, Jones A, Naughton F. A systematic review of just-intime adaptive interventions (JITAIs) to promote physical activity. Int J Behav Nutr Phys Act. 2019 Apr; 16(1):31.

142 Hébert ET, Ra CK, Alexander AC, Helt A, Moisiuc R, Kendzor DE, et al. A Mobile Justin-Time Adaptive Intervention for Smoking Cessation: Pilot Randomized Controlled Trial. J Med Internet Res. 2020 Mar; 22(3):e16907.

143 Demrozi F, Pravadelli G, Tighe PJ, Bihorac A, Rashidi P. Joint Distribution and Transitions of Pain and Activity in Critically Ill Patients. Annu Int Conf IEEE Eng Med Biol Soc. 2020 Jul;2020:4534-8.

144 Jacobson NC, O'Cleirigh C. Objective digital phenotypes of worry severity, pain severity and pain chronicity in persons living with HIV. Br J Psychiatry. 2021 Mar;218(3): 165-7.

145 Leininger B, Schulz C, Gao Z, Bronfort G Evans R, Pope Z, et al. Accelerometer-Determined Physical Activity and Clinical Low Back Pain Measures in Adolescents With Chronic or Subacute Recurrent Low Back Pain. J Orthop Sports Phys Ther. 2017 Oct; 47(10):769-74.

146 Motl RW, McAuley E, Snook EM, Gliottoni RC. Physical activity and quality of life in multiple sclerosis: intermediary roles of disability, fatigue, mood, pain, self-efficacy and social support. Psychol Health Med. 2009 Jan;14(1):111-24. 